\title{
Increased hyaluronic acid content in idiopathic pulmonary arterial hypertension
}

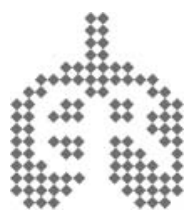

\author{
E. Papakonstantinou*, F.M. Kouri",๘, G. Karakiulakis*, \\ I. Klagas* and O. Eickelberg*
}

ABSTRACT: Idiopathic pulmonary arterial hypertension (IPAH) is a fatal disease characterised by elevated blood pressure in the pulmonary circulation. Initial vasoconstriction, proliferation of pulmonary arterial smooth muscle cells (PASMC) and increased deposition of extracellular matrix (ECM) contribute to pathological remodelling of pulmonary arterioles in IPAH. Glycosaminoglycans (GAGs), components of the ECM, control cellular proliferation and differentiation, but their expression in IPAH remains elusive.

In the present study, GAG expression was investigated in the lungs of patients with IPAH or control transplant donors, and expression and localisation of GAG-metabolising enzymes were analysed in vivo and in vitro.

A significant increase in the expression of hyaluronic acid (HA) was detected in IPAH lungs, associated with increased hyaluronan synthase (Has) 1 and decreased hyaluronoglucosaminidase 1 gene expression, as assessed by quantitative RT-PCR and Western blotting. HAS1 protein localised to PASMC in vivo and increased HA deposition was observed in remodelled pulmonary arteries in IPAH. Transforming growth factor- $\beta 1$, a profibrotic growth factor, led to increased HA secretion and HAS1 expression in primary PASMC.

The results demonstrate an increased hyaluronic acid content in idiopathic pulmonary arterial hypertension lungs, associated with increased hyaluronan synthase 1 and decreased hyaluronoglucosaminidase 1 gene expression. Synergistic regulation of glycosaminoglycan-metabolising enzymes in favour of accumulation may, thus, regulate pathological vascular remodelling in idiopathic pulmonary arterial hypertension lungs.

KEYWORDS: Hyaluronic acid, pulmonary arterial hypertension, pulmonary arterial smooth muscle cells, transforming growth factor- $\beta 1$, vascular remodelling

diopathic pulmonary arterial hypertension

(IPAH) is a rare but fatal disease characterised

by elevated blood pressure in the pulmonary circulation due to increased vascular resistance of pulmonary arterioles [1, 2]. If untreated, IPAH leads to right ventricular hypertrophy and failure and subsequent death. Early in disease pathogenesis, endothelial cell dysfunction triggers increased vasoconstriction and in situ thrombosis. This is followed by pathological vascular remodelling, a process characterised by intimal fibrosis and thickening of the medial and adventitial layers due to uncontrolled proliferation of pulmonary arterial smooth muscle cells (PASMC) and perivascular fibroblasts [3-5]. In parallel, enhanced cellular activation of PASMC and fibroblasts leads to excessive extracellular matrix (ECM) deposition, which potentiates the increased stiffness of pulmonary arteries in IPAH [6, 7].

Altered ECM turnover is a hallmark of several pulmonary diseases, including adult respiratory distress syndrome, asthma, idiopathic pulmonary fibrosis, or chronic obstructive lung disease, which underlines the importance of ECM homeostasis for proper lung function [7-9]. In the lung, the ECM is subjected to a daily turnover of $\sim 10 \%$ of total ECM, indicating that subtle changes in turnover rates accumulate to produce large changes in total ECM composition with time [10]. The ECM is largely composed of collagens, fibronectin, vitronectin, proteoglycans and glycosaminoglycans (GAGs) [11]. GAGs are linear acidic polysaccharides of variable length and composition that are grouped into four major categories: hyaluronic acid (HA); heparin and heparan sulphate (HS); chondroitin and dermatan sulphates (CS and DS, respectively); and keratan sulphate [12, 13]. GAGs have previously been shown to control lung inflammation, as well as the phenotype of systemic vascular smooth muscle cells [14-16].

$\mathrm{HA}$ is a major component of the basement membrane and constitutes $\sim 10 \%$ of all proteoglycans [17].

\section{AFFILIATIONS}

*Dept of Pharmacology, Aristotle University School of Medicine, Thessaloniki, Greece.

\#Dept of Medicine, University of Giessen Lung Center, Justus-LiebigUniversity, Giessen, Germany.

"Both authors contributed equally to this article.

CORRESPONDENCE

0 . Eickelberg

University of Giessen Lung Center Dept of Medicine II, Aulweg 123, Room 6-11, D-35392 Giessen, Germany.

Fax: 496419942309

E-mail: oliver.eickelberg@

innere.med.uni-giessen.de

Received:

November 262007

Accepted after revision:

August 152008

SUPPORT STATEMENT

E. Papakonstantinou was the recipient of a European Respiratory Society short-term fellowship (№. 382). This work was supported by the German Research Foundation (DFG)

Collaborative Research Center 547 (grant to 0. Eickelberg), the DFGsponsored international graduate program "Signalling Mechanisms in Lung Physiology and Disease" (grant to F.M. Kouri and 0. Eickelberg), the "Excellence Cluster Cardio-

Pulmonary System" (Justus-LiebigUniversity, Giessen, Max-Planck-

Institute for Heart and Lung Research, Bad Nauheim, Johann Wolfgang Goethe University, Frankfurt-am-

Main, all Germany), and the General Secretariat for Research and

Technology, Athens, Greece (grant 03E $\Delta$ 950)

STATEMENT OF INTEREST

None declared.

European Respiratory Journa

Print ISSN 0903-1936

Online ISSN 1399-3003 
HA is synthesised at the inner surface of the plasma membrane by one or more hyaluronan synthase (HAS) isoforms (HAS1, -2 or -3), which exhibit distinct enzymatic properties and synthesise HA chains of various average chain length [18]. After synthesis, HA chains are extruded through pore-like structures into the extracellular space. Alternatively, HA can be degraded by one of four hyaluronoglucosaminidase (HYAL) isoforms (HYAL1-4). HYAL1, the main hyaluronoglucosaminidase, exhibits the highest hyaluronidase activity and, thus, represents the major enzyme for HA degradation [19].

HA can influence cellular responses in several ways. First, the interaction of HA with pericellular macromolecules leads to softening of the ECM, thereby facilitating cell shape changes that are required for cell division, migration or plasticity [2022]. As a result, increased levels of HA have been implicated in inflammation, morphogenesis, regeneration, wound healing, tumour invasion or cancer metastasis [21-23]. Secondly, HA can directly interact with the cell surface receptors CD44 and the receptor for hyaluronan-mediated motility (RHAMM), which directly transduce intracellular signalling cascades via extracellular signal-regulated kinase 1/2 [12, 24, 25].

CD44 and HA expression was increased after lung injury induced by the DNA-damaging chemotherapeutic agent bleomycin and mediated pro-inflammatory mediator release by alveolar macrophages [26]. Increased HA content was detected in atherosclerotic regions $[20,27,28]$ and HA has been shown to induce smooth muscle cell migration [29]. Overall, this suggests the potential involvement of HA in remodelling of the systemic vasculature, but its contribution to pulmonary vascular remodelling in IPAH remains elusive. In the present study, GAG expression was investigated in lung tissues of IPAH patients and control transplant donors, and the expression and localization of HA metabolizing enzymes were analysed in human lung samples and PASMC in vivo and in vitro, respectively.

\section{MATERIALS AND METHODS Lung tissues and primary PASMC}

Lung tissue samples were obtained during lung transplantation from 12 patients with IPAH (mean \pm SD age $32 \pm 10$ yrs, seven females, five males; table 1) and nine control subjects (organ donors, age $38 \pm 14$ yrs, five females, four males). None of the IPAH patients exhibited bone morphogenetic receptor type II (BMPR2) mutations. For tissue processing, all samples were immediately placed in $4 \%(\mathrm{w} / \mathrm{v})$ paraformaldehyde or liquid nitrogen after explantation. The study protocol was approved by the Ethics Committee of the Justus-LiebigUniversity School of Medicine (Giessen, Germany; AZ 31/ 93). Informed consent was obtained from each subject for the study protocol. Primary PASMC were generated from arteries of IPAH or donor lungs derived from explanted lung tissues, as indicated, and prepared for isolation of PASMC, as previously described [30]. Cells were cultured in smooth muscle cell growth medium 2 (PromoCell, Heidelberg, Germany) at $37^{\circ} \mathrm{C}$ in a $5 \% \quad \mathrm{CO}_{2}, 95 \% \quad \mathrm{O}_{2}$ atmosphere. Passages three to seven were used for the experiments.

\section{GAG isolation and purification}

Lung tissue specimens were homogenised at $4^{\circ} \mathrm{C}$ using a Polytron homogeniser in $25 \mathrm{mM}$ Tris- $\mathrm{HCl}, \mathrm{pH}$ 7.6 (10 mL per g of tissue). Homogenised tissues were delipidated in chloroform/methanol $(1: 2 \mathrm{v} / \mathrm{v})$. Organic solvents were removed by centrifugation (at $3,200 \times g$ for $20 \mathrm{~min}$ at $4^{\circ} \mathrm{C}$ ) and the pellet was washed with $10 \mathrm{~mL}$ ethanol, centrifuged as before and dried at $40^{\circ} \mathrm{C}$ for $4 \mathrm{~h}$. The remaining pellet was then resuspended in $0.1 \mathrm{M}$ Tris- $\mathrm{HCl}, \mathrm{pH} 8.0,1 \mathrm{mM} \mathrm{CaCl}_{2}$, and GAGs were isolated and purified following digestion with pronase (from Streptomyces griseus; EMD Chemicals Inc., San Diego, CA, USA), DNase I (EC 3.1.21.1; Calbiochem, EMD Chemicals Inc.) and $\beta$-elimination in the presence of $1 \mathrm{M}$ $\mathrm{NaBH}_{4}$ [20]. Total GAGs were precipitated with four volumes of ethanol in the presence of 0.1 volumes of $3 \mathrm{M}$ sodium acetate overnight at $-4^{\circ} \mathrm{C}$, recovered with centrifugation $(20 \mathrm{~min}$ at $2,000 \times g$ ), dissolved in double-distilled $\mathrm{H}_{2} \mathrm{O}$ and stored at $4{ }^{\circ} \mathrm{C}$. Colorimetric determination of uronic acids was performed as previously described [31].

\section{Cellulose acetate electrophoresis}

Samples of $2 \mu \mathrm{L}$ of GAG solution, containing $4 \mu \mathrm{g}$ of uronic acids, were subjected to cellulose acetate electrophoresis in $100 \mathrm{mM}$ pyridine, $470 \mathrm{mM}$ formic acid, $\mathrm{pH} 3.0$, using $7 \mathrm{~mA}$ constant current, at room temperature for $70 \mathrm{~min}$. Commercially available GAG standards used as markers included HA, HS, DS and CS (all from Sigma-Aldrich, St Louis, MO, USA). After electrophoresis, the cellulose acetate strip was stained with $0.2 \%$ Alcian blue $(\mathrm{w} / \mathrm{v})$ in $0.1 \%$ acetic acid $(\mathrm{v} / \mathrm{v})$ for $10 \mathrm{~min}$ and washed with $0.1 \%$ acetic acid $(\mathrm{v} / \mathrm{v})$ for $20 \mathrm{~min}$ [20]. Staining intensity was quantified using a computer-assisted image analysis programme according to the manufacturer's recommendation (Eastman Kodak, Rochester, NY, USA).

\section{GAG characterisation}

Speed-dried GAGs (5 $\mu \mathrm{g}$ of uronic acids) were incubated in a final volume of $15 \mu \mathrm{L}$ with the following enzymes. 1) Heparinase: samples were dissolved in $100 \mathrm{mM}$ Tris- $\mathrm{HCl}$ buffer, $\mathrm{pH} 7.0$, containing $3 \mathrm{mM} \mathrm{CaCl}_{2}$, and incubated with $4 \times 10^{-4}$ U heparin lyase I (EC 4.2.2.7, Flavobacterium heparinum;

\begin{tabular}{|c|c|c|c|c|c|}
\hline TABLE 1 & \multicolumn{5}{|c|}{$\begin{array}{l}\text { Characteristics of idiopathic pulmonary arterial } \\
\text { hypertension (IPAH) patients }\end{array}$} \\
\hline Patient & Diagnosis & Sex & Age yrs & Ppa $\mathrm{mmHg}$ & Treatment \\
\hline 1 & IPAH & $\mathrm{F}$ & 26 & NA & NA \\
\hline 2 & IPAH & M & 21 & NA & Prostacyclin \\
\hline 3 & IPAH & $\mathrm{F}$ & 28 & 95 & NO, Bosentan \\
\hline 4 & IPAH & M & 44 & 83 & Prostacyclin \\
\hline 5 & IPAH & $\mathrm{F}$ & 52 & 92 & Prostacyclin \\
\hline 6 & IPAH & M & 28 & 80 & Prostacyclin \\
\hline 7 & IPAH & $F$ & 43 & NA & Bosentan \\
\hline 8 & IPAH & $F$ & 40 & 56 & Bosentan \\
\hline 9 & IPAH & M & 45 & 81 & Sildenafil \\
\hline 10 & IPAH & M & 30 & 95 & Remodulin \\
\hline 11 & IPAH & $\mathrm{F}$ & 20 & NA & Sildenafil \\
\hline 12 & IPAH & $\mathrm{F}$ & 12 & NA & NA \\
\hline $\begin{array}{l}\text { None of } \\
\text { Ppa: pul } \\
\text { nitric oxi }\end{array}$ & $\begin{array}{l}\text { he patients e } \\
\text { lonary arteria } \\
\text { le. }\end{array}$ & $\begin{array}{l}\text { ited } k \\
\text { essur }\end{array}$ & $\begin{array}{l}\text { morphoge } \\
\text { : female; } 1\end{array}$ & $\begin{array}{l}\text { etic receptor } \\
\text { male; NA: } n\end{array}$ & $\begin{array}{l}\text { oe II mutations. } \\
\text { available; NO: }\end{array}$ \\
\hline
\end{tabular}


Seikagaku, Tokyo, Japan) for $15 \mathrm{~h}$ at $30^{\circ} \mathrm{C}$. 2) Heparitinase: samples were similarly dissolved and incubated with $4 \times 10^{-4} \mathrm{U}$ heparan sulphate lyase (heparitinase: EC 4.2.2.8, Flavobacterium heparinum; Seikagaku) for $16 \mathrm{~h}$ at $43^{\circ} \mathrm{C}$. 3) Chondroitinase ABC: samples were dissolved in $100 \mathrm{mM}$ Tris- $\mathrm{HCl}$ buffer, $\mathrm{pH} 8.0$, containing $50 \mathrm{mM}$ sodium acetate, and incubated with $2 \times 10^{-4} \mathrm{U}$ chondroitin ABC lyase (EC 4.2.2.4, Proteus vulgaris; Sigma-Aldrich) for $16 \mathrm{~h}$ at $37^{\circ} \mathrm{C}$. 4) Chondroitinase B: samples were dissolved in $100 \mathrm{mM}$ Tris$\mathrm{HCl}$ buffer, $\mathrm{pH} 7.4$, and incubated with $0.1 \mathrm{U}$ chondroitin $\mathrm{B}$ lyase (Flavobacterium heparinum; Seikagaku) for $16 \mathrm{~h}$ at $37^{\circ} \mathrm{C}$. 5) Keratanase: samples were dissolved in $50 \mathrm{mM}$ Tris- $\mathrm{HCl}$ buffer, pH 7.4, and incubated with $0.05 \mathrm{U}$ keratan sulphate endo- $\beta$-D-galactosidase (EC 3.2.10.3, Pseudomonas species; Sigma-Aldrich) for $16 \mathrm{~h}$ at $37^{\circ} \mathrm{C}$. 6) Hyaluronidase: samples were dissolved in $20 \mathrm{mM}$ sodium acetate, buffered with acetic acid to $\mathrm{pH} 5.0$, and incubated with $4 \mathrm{U}$ hyaluronate lyase (EC 4.2.2.1, Streptomyces hyalurolyticus; Seikagaku) for $14 \mathrm{~h}$ at $60^{\circ} \mathrm{C}$. Incubation times and enzyme concentrations were as required for complete degradation of standard substrates, as previously described [32].

\section{HA measurements}

To analyse secreted HA, primary PASMC were grown to subconfluence in 24-well plates. Cells were then stimulated with transforming growth factor (TGF)- $\beta 1 \quad(0.2,2$ or $10 \mathrm{ng} \cdot \mathrm{mL}^{-1}$, as indicated) for 6,12 or $24 \mathrm{~h}$. At the end of the incubation time, aliquots of culture media were removed and HA content measured by ELISA according to the manufacturer's instructions (Corgenix, Westminster, CO, USA). Similarly, HA content in lung specimen and cell lysates were determined by ELISA. To measure de novo GAG synthesis, subconfluent primary PASMC were incubated for $24 \mathrm{~h}$ in the presence or absence of TGF- $\beta 1\left(0.2\right.$ or $2 \mathrm{ng} \cdot \mathrm{mL}^{-1}$, as indicated), bone morphogenetic protein (BMP)-2 (10 or $20 \mathrm{ng} \cdot \mathrm{mL}^{-1}$, as indicated), the type I TGF- $\beta$ receptor kinase inhibitor SB431542
$(10 \mu \mathrm{M})$, the p38 inhibitor SB203580 $(10 \mu \mathrm{M})$ or platelet-derived growth factor (PDGF)-BB $\left(10 \mathrm{ng} \cdot \mathrm{mL}^{-1}\right)$. The $\left[{ }^{3} \mathrm{H}\right]$-glucosamine $\left(0.5 \mu \mathrm{Ci} \cdot \mathrm{mL}^{-1}\right.$; Amersham Corp., Little Chalfont, UK) was then added to culture media for another $24 \mathrm{~h}$. Culture media and cell layers were then collected and digested with $0.1 \mathrm{kU}$ pronase. Total GAGs were precipitated by adding a mixture of ethanol (80\% final concentration) containing $1.3 \%(\mathrm{w} / \mathrm{v})$ sodium acetate. The samples were stored at $-20^{\circ} \mathrm{C}$ overnight and centrifuged at $10,000 \times g$, the pellets were dissolved in $0.5 \mathrm{M} \mathrm{NaOH}$ and total GAG synthesis was measured by liquid scintillation counting, as previously described [16].

\section{Immunohistochemistry}

Human paraffin-embedded lung specimens $(3 \mu \mathrm{m})$ from healthy donors or IPAH patients were stained with biotinylated hyaluronan-binding protein (HABP; Seigakaku), smooth muscle $\alpha$-actin ( $\alpha$-SMA; Sigma-Aldrich), HYAL1 (Novus Biologicals, Littleton, CO, USA) or HAS1 (Santa Cruz Biotechnology, Santa Cruz, CA, USA) antibodies, using the Histostain Plus Kit (Zymed, San Francisco, USA) as previously described [30]. Sections pre-incubated with $50 \mathrm{U} \cdot \mathrm{mL}^{-1}$ of hyaluronate lyase (EC 4.2.2.1, Streptomyces hyalurolyticus; Seikagaku) for $3 \mathrm{~h}$ at $37^{\circ} \mathrm{C}$ served as negative controls for $\mathrm{HABP}$, and sections incubated with isotype-matched preimmune serum served as negative controls for $\alpha$-SMA, HYAL1 and HAS1 immunostaining.

\section{Quantitative RT-PCR}

Total RNA was extracted using QIAGEN extraction kits according to the manufacturer's protocols (QIAGEN, Hilden, Germany) and cDNAs were generated by reverse transcription using SuperScript ${ }^{\mathrm{TM}}$ II (Invitrogen, Carlsbad, CA, USA). Quantitative (q) PCR was performed using fluorogenic SYBR Green and the Sequence Detection System 7700 (PE Applied Biosystems, Foster City, CA, USA) [30]. Human hydroxymethylbilane synthase, a ubiquitously and equally expressed

\begin{tabular}{|c|c|c|c|c|c|c|}
\hline \multirow{3}{*}{$\begin{array}{l}\text { TABLE } 2 \\
\text { Gene }\end{array}$} & \multicolumn{6}{|c|}{$\begin{array}{l}\text { Primer sequences and amplicon sizes used for the analysis of human lung tissues and pulmonary arterial smooth } \\
\text { muscle cells }\end{array}$} \\
\hline & \multirow[t]{2}{*}{ Accession No. } & \multicolumn{2}{|c|}{ Forward primer } & \multicolumn{2}{|c|}{ Reverse primer } & \multirow[t]{2}{*}{ Amplicon size bp } \\
\hline & & Sequence & Length bp & Sequence & Length bp & \\
\hline Has1 & NM001523 & gcgatactgggtagccttca & 20 & ggttgtaccaggectcaaga & 20 & 131 \\
\hline Hyal1 & NM007312 & gtgctgccctatgtccagat & 20 & atttcccagctcacccaga & 20 & 132 \\
\hline Hyal2 & NM033158 & tctaccattggcgagagtg & 19 & gcagccgtgtcaggtaat & 19 & 119 \\
\hline Hyal3 & NM003549 & gatctgggaggttcctgtcc & 20 & agagctggagaggctcaggt & 20 & 110 \\
\hline Hyal4 & NM012269 & tgaggatctccaccatgaca & 20 & ggcagcactttctcctatgg & 20 & 134 \\
\hline Cd44 & NM000610.3 & cccagatggagaaagctctg & 20 & gttgtttgctgcacagatgg & 20 & 113 \\
\hline
\end{tabular}

All primer sets were designed to work under identical real-time PCR cycling conditions and simultaneous amplifications were obtained in the same run. Sequences were according to GeneBank reference sequences. Primer sequences are given in 5'-3' orientation. Has: hyaluronan synthase; Hyal: hyaluronoglucosaminidase; Rhamm: receptor for hyaluronan-mediated motility; Hmbs: hydroxymethylbilane synthase. 
a)
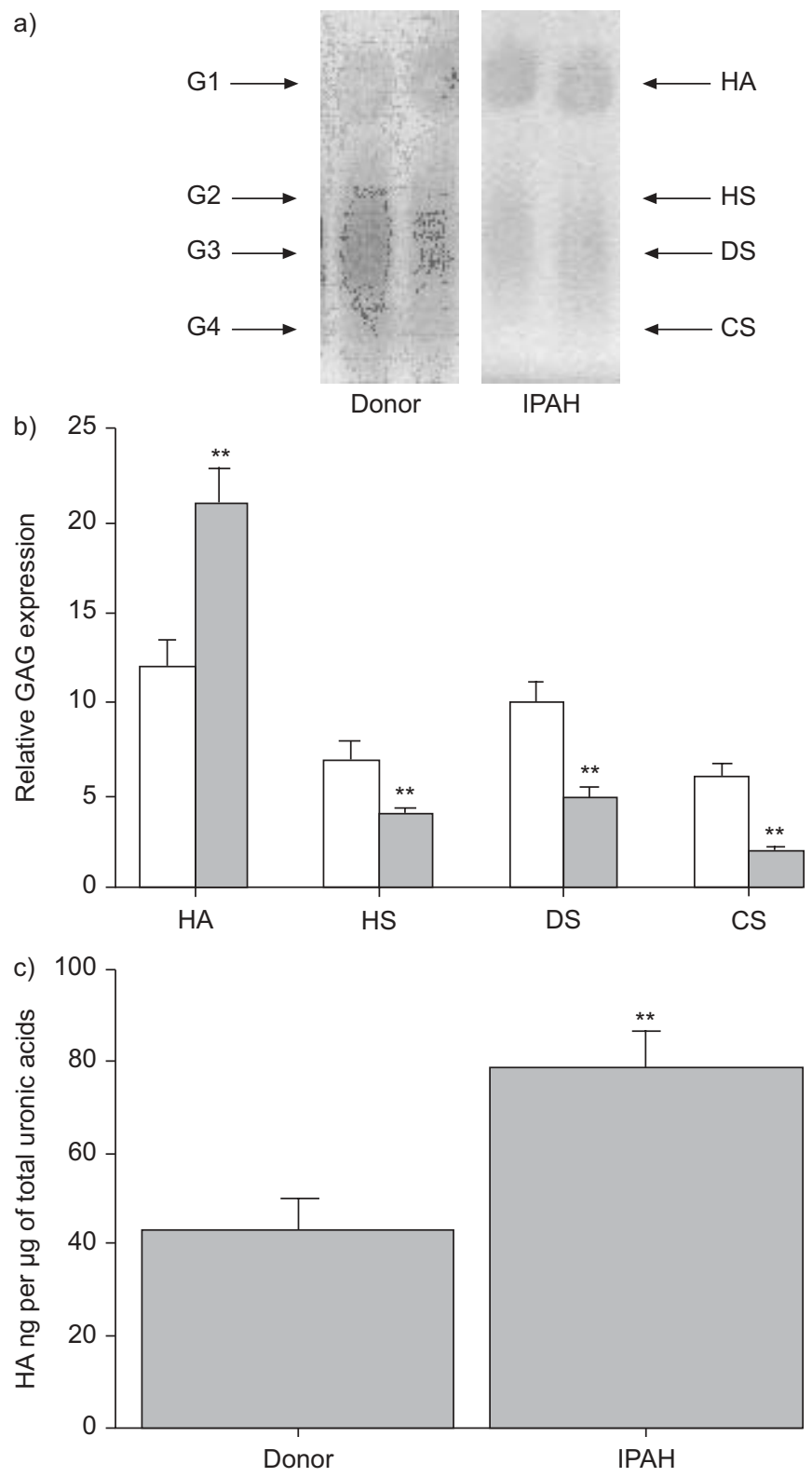

FIGURE 1. Glycosaminoglycan (GAG) expression in idiopathic pulmonary arterial hypertension (IPAH) and control lung tissue samples. a) Representative cellulose acetate membranes demonstrating the electrophoretic separation of total GAG in donor and IPAH lung specimens. G1-G4: four detectable GAG peaks in lung tissues. Commercially available GAG standards were as follows. HA: hyaluronic acid; HS: heparan sulphate; DS: dermatan sulphate; CS: chondroitin sulphate. b) Densitometric quantitation of mean \pm SEM values of alcian blue staining of the electrophoretic separation of GAGs. $\square$ : donor; $\square$ : IPAH. c) Measurement by ELISA of the relative content of HA in aliquots of total GAG containing $0.15 \mu \mathrm{g}$ of uronic acids. Data are presented as mean \pm SEM. For all investigations, samples from four donor and five IPAH lung tissue specimens were used. ${ }^{*}$ : $p<0.01$.

gene free of pseudogenes, was used as a reference gene in all qRT-PCR reactions. PCRs were performed using the primers listed in table 2 at a final concentration of $200 \mathrm{nM}$. Relative transcript abundance of a gene was expressed as the change in threshold cycle $(\mathrm{Ct})$ values $(\mathrm{Ct}$ for reference minus $\mathrm{Ct}$ for target), as previously described in detail [30].

\section{RESULTS}

\section{Expression of GAG in IPAH}

Electrophoretic analysis of total GAG isolated and purified from lung tissue specimens from IPAH patients or healthy donors revealed the presence of four distinct GAG populations (G1-G4) in donor and IPAH lungs (fig. 1a). Enzymatic treatment with specific GAG-degrading enzymes (table 3), as well as comparison with the electrophoretic mobility of commercially available GAG standards (fig. 1a), identified G1 as HA, G2 as HS, G3 as DS and G4 as CS. Densitometric analysis of alcian blue staining of these GAGs revealed a significant increase in HA content and a significant decrease in the content of HS, DS and CS in IPAH tissue specimens, compared with donors (fig. 1b). In order to further quantify the increase in HA, the HA concentration was measured within total GAG in lung specimens by ELISA. As shown in figure 1c, the relative amount of HA in the lungs of IPAH patients was significantly increased, compared with lung tissues from transplant donors (mean \pm SEM $78.6 \pm 7.83$ versus $43.175 \pm 6.87 \mathrm{ng}$ per $\mu \mathrm{g}$ of total uronic acids for IPAH and donor lungs, respectively).

\section{Localisation of GAG in IPAH}

To further localise HA and its main metabolizing enzymes HAS1 and HYAL1 in the lungs of IPAH patients or transplant donors, immunohistochemical staining was performed. As depicted in figure 2, HA expression could be detected throughout the alveolar interstitium, in the perivascular and peribronchiolar adventitia and in the endothelium. In remodelled lesions in IPAH, HA also frequently localised to subendothelial areas that stained negative for $\alpha$-SMA (fig. $2 \mathrm{i}$ and j), indicating that it is expressed in areas of dedifferentiated PASMC. In contrast, HAS1 and HYAL1 expression was dominant in PASMC, suggesting that $\mathrm{HA}$ is synthesised by PASMC and subsequently secreted towards the adventitia. While HYAL1 expression was attenuated in IPAH, significant HYAL1 expression was retained in bronchial and alveolar epithelial type II cells (fig. $2 \mathrm{~h}$ ). Staining using tissue sections pre-digested with hyaluronidase or speciesmatched isotype controls exhibited no positive staining, indicating specificity of the antibodies used (data not shown).

\section{Expression of GAG-metabolising enzymes in IPAH in vivo and PASMC in vitro}

Since the expression of HA was increased in IPAH, Has and Hyal mRNA expression was quantified in lung tissue specimens and primary PASMC using qRT-PCR. As depicted in figure 3a, Has1-3, Hyal1-3, CD44 and Rhamm were all expressed in the human lung, while Hyal4 mRNA was expressed only at very low levels. When comparing expression levels in donor and IPAH lungs, significantly increased expression levels of Has1 and CD44 but decreased levels of Hyal1 were detected in IPAH (fig. 3a). Increased HAS1 protein expression in IPAH lungs was confirmed by Western blot analysis (fig. 3b).

As the immunohistochemical data (fig. 2) indicated that HAS1 and HYAL1 were localised to PASMC in vivo, and PASMC represent a key pathogenic cell type in IPAH, primary PASMC were isolated from IPAH and donor patients and Has1 and Hyal1 mRNA expression was assessed by qRT-PCR (fig. 4). While no differences were observed in Has1 mRNA expression, 


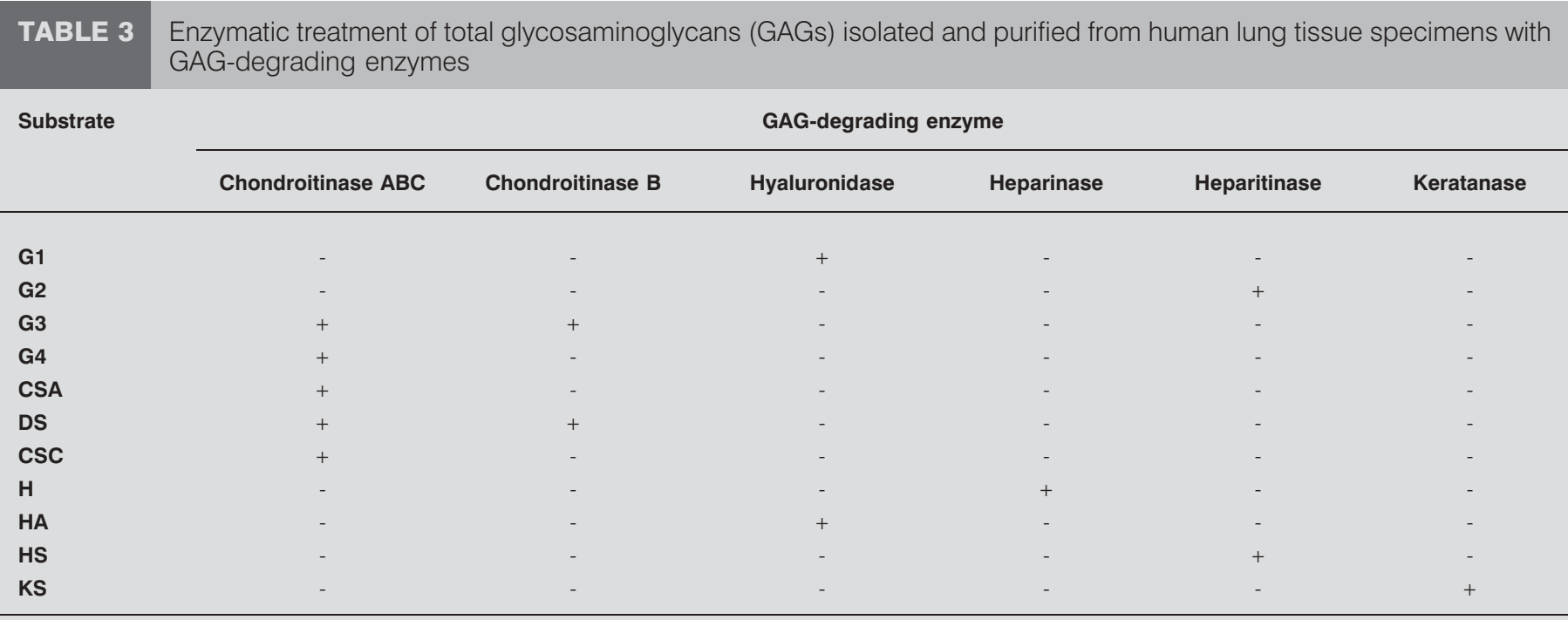

Total GAGs isolated and purified from human lung tissue specimens of donors $(n=5)$ or idiopathic pulmonary arterial hypertension patients $(n=5)$ were treated with the indicated GAG-degrading enzymes. The digestion was monitored by cellulose acetate electrophoresis. Data represent observations from five different lung tissue specimens. G1-G4: GAG populations obtained following cellulose acetate electrophoresis, numbers correspond to those of figure 1a; CSA: chondroitin sulphate A; DS: dermatan sulphate B; CSC: chondroitin sulphate C; H: heparin; HA: hyaluronic acid; HS: heparan sulphate; KS: keratan sulphate; +: 100\% degradation; -: no detectable degradation.
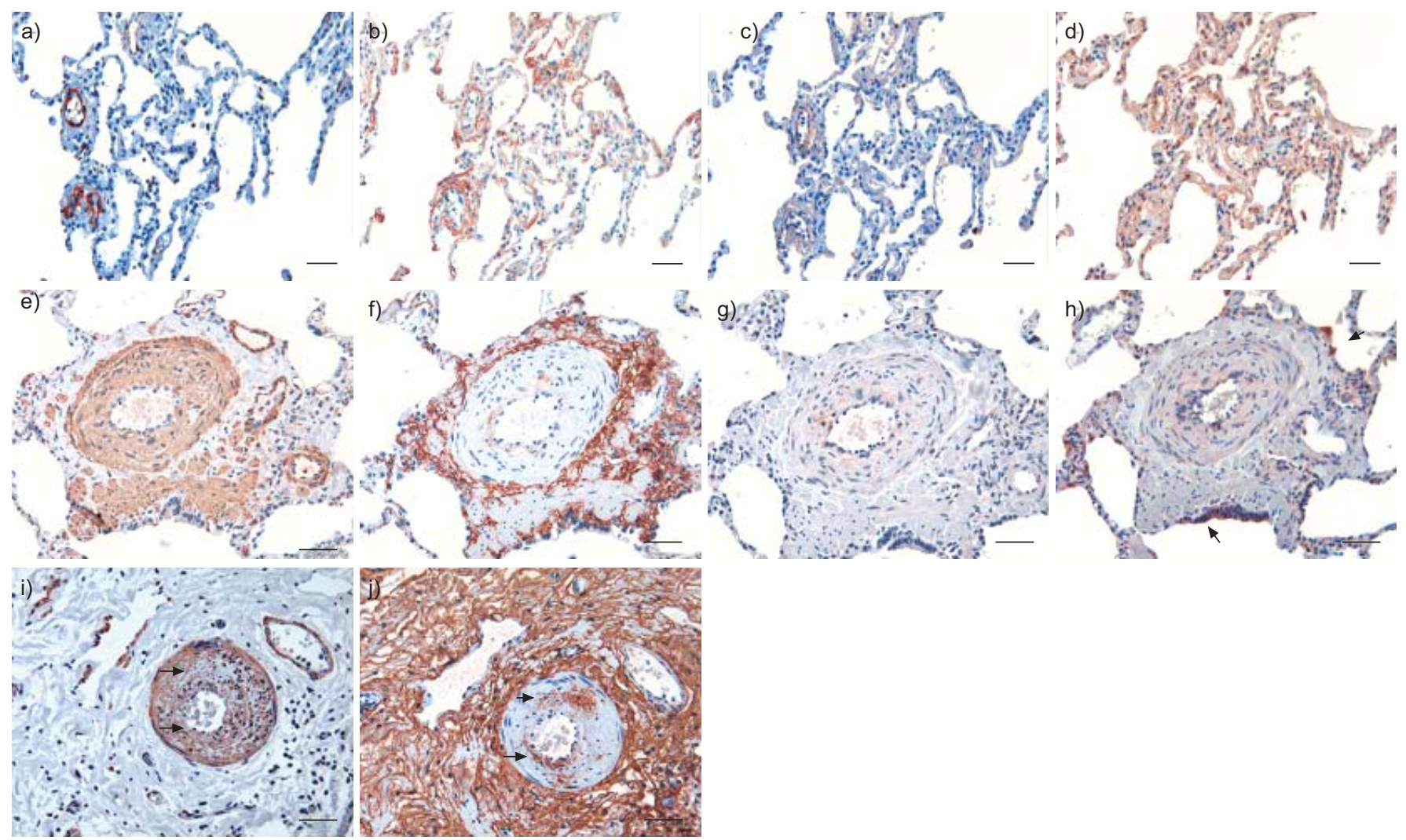

FIGURE 2. Localisation of smooth muscle $\alpha$-actin ( $\alpha$-SMA; a, e and i), hyaluronan-binding protein (HABP; $b, f$ and j), hyaluronan synthase (HAS) 1 (c and g) and hyaluronoglucosaminidase (HYAL)1 $(\mathrm{d}$ and $\mathrm{h}$ ) in pulmonary arteries of control transplant donors $(\mathrm{a}-\mathrm{d})$ and idiopathic pulmonary arterial hypertension (IPAH) patients (e-j) was assessed by immunohistochemistry. Hyaluronic acid (HA) was visualised by staining with HABP, while $\alpha$-SMA, HAS1 and HYAL1 were stained using specific antibodies. Sections are representative for at least four different donors or IPAH patients. h) Arrows indicate HYAL1 expression in bronchial and alveolar epithelial type II cells in IPAH. i and j) Arrows indicate HA expression in pulmonary arterial smooth muscle cells in remodelled lesions that are negative for $\alpha$-SMA. Scale bars $=50 \mu \mathrm{m}$. 


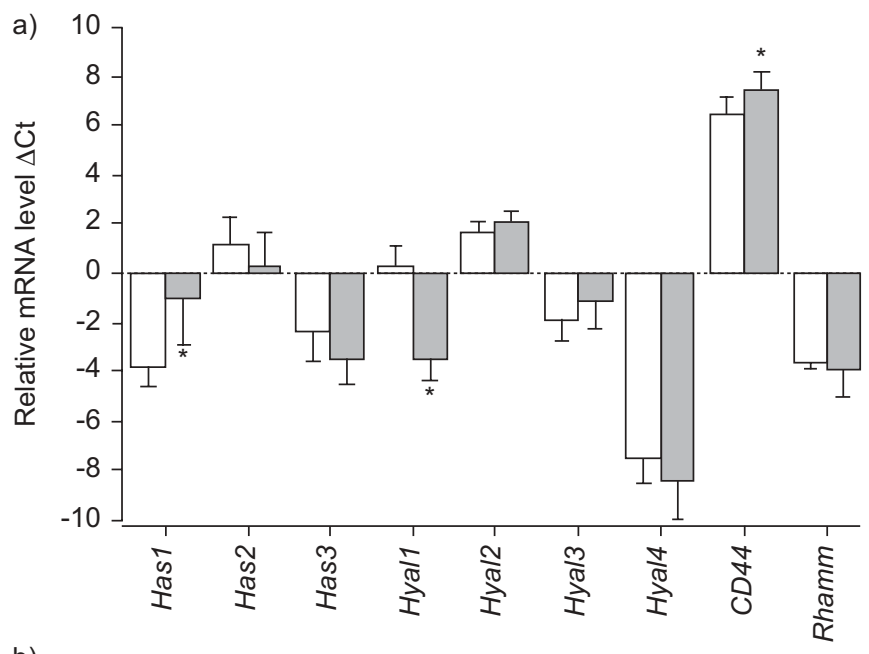

b)

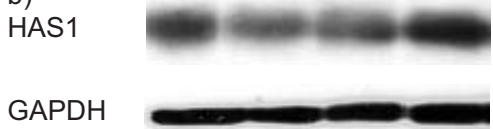

Donor
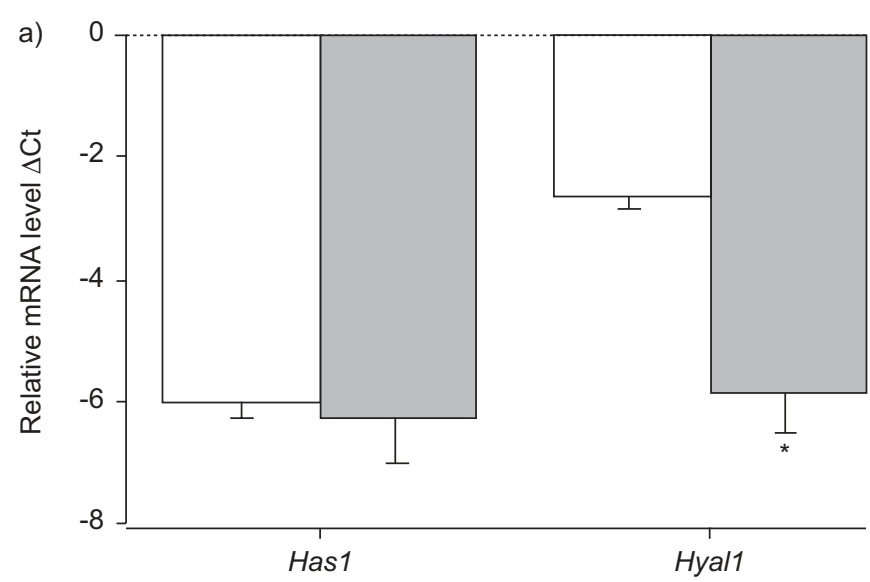

FIGURE 4. Differential expression of hyaluronoglucosaminidase (Hyal) 1 in pulmonary arterial smooth muscle cells (PASMC) derived from the lungs of idiopathic pulmonary arterial hypertension (IPAH) patients. The hyaluronan synthase (Has) 1 and Hyal1 mRNA levels were assessed in primary PASMC isolated from donors $(\square, n=3)$ and IPAH $(\square, n=6)$ lungs by quantitative RT-PCR. Data are presented as mean \pm SEM relative expression level, as change in threshold cycle $(\Delta \mathrm{Ct})$ values. *: $p<0.05$.

SB203580 pre-treatment inhibited TGF- $\beta 1$-induced but not basal GAG deposition by PASMC (fig. 5b).

\section{Secretion of HA by PASMC}

In order to further investigate whether the TGF- $\beta 1$-dependent increase in $\left[{ }^{3} \mathrm{H}\right]$-glucosamine incorporation was in part a result of increased HA secretion, HA secretion by PASMC was measured by ELISA. As depicted in figure 6, PASMC secreted considerable amounts of HA under baseline conditions, and this secretion was significantly enhanced by TGF- $\beta 1$ in a timedependent manner. While high TGF- $\beta 1$ concentrations $\left(10 \mathrm{ng} \cdot \mathrm{mL}^{-1}\right)$ led to a significant increase in HA secretion already after $12 \mathrm{~h}$, physiological concentrations of TGF- $\beta 1$ (0.2$2 \mathrm{ng} \cdot \mathrm{mL}^{-1}$ ) significantly increased HA secretion by PASMC only after $24 \mathrm{~h}$ (fig. 6).

\section{Expression of GAG-metabolising enzymes in PASMC}

The time-course of TGF- $\beta 1$-induced HA secretion indicated that de novo gene expression of Has1-3 or repression of Hyal1-3 may be required for the increase in HA. Therefore, Has and Hyal mRNA expression was assessed in primary human PASMC that were stimulated with TGF- $\beta 1$ for $\leqslant 6 \mathrm{~h}$. Using qRT-PCR, a significant increase in Has1 gene expression was detected as early as $2 \mathrm{~h}$ after TGF- $\beta 1$ stimulation of PASMC, and there was an even further increase after $6 \mathrm{~h}$ (fig. 7). In contrast, TGF- $\beta 1$ had no significant effect on the expression of Has2 or -3, Hyal1-3, CD44 or Rhamm (fig. 6). Interestingly, Hyal4 was not expressed in PASMC and was, therefore, not included in fig. 7.

\section{DISCUSSION}

Despite major recent advances in the pathophysiology, diagnosis and therapy of IPAH, the molecular mechanisms underlying endothelial and smooth muscle cell dysfunction in this disease remain to be fully elucidated [4]. Initial endothelial dysfunction contributes to impaired vasoregulation and is accompanied by dysregulated release of soluble mediators. 

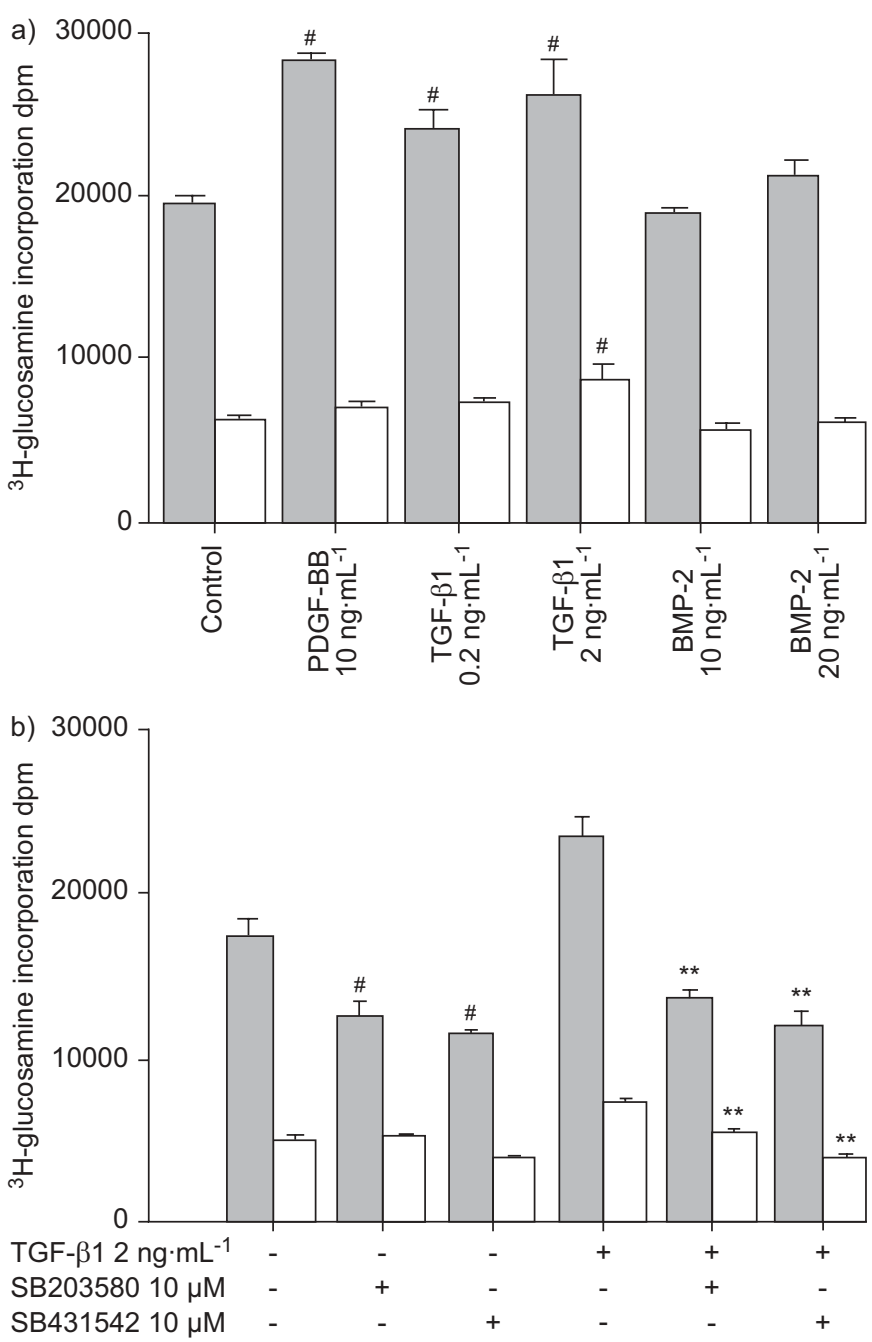

FIGURE 5. Effect of transforming growth factor (TGF)- $\beta 1$ on glycosaminoglycan (GAG) secretion and deposition by pulmonary arterial smooth muscle cells (PASMC). a) Subconfluent primary human PASMC were incubated with plateletderived growth factor (PDGF)-BB, TGF- $\beta 1$ or bone morphogenetic protein (BMP)-2 for $24 \mathrm{~h}$, in the presence of $\left[{ }^{3} \mathrm{H}\right]$-glucosamine at $0.5 \mu \mathrm{Ci} \cdot \mathrm{mL}^{-1}$. Incorporation of $\left[{ }^{3} \mathrm{H}\right]$ glucosamine was then assessed in supernatants (representing secreted GAG; $\square$ ) and cell layers (representing deposited GAG; $\square$ ). b) Subconfluent primary PASMC were stimulated with TGF- $\beta 1$ in the presence or absence of the $\mathrm{p} 38$ kinase inhibitor SB203580 or the type I TGF- $\beta 1$ receptor kinase inhibitor SB431542, and the incorporation of $\left[{ }^{3} \mathrm{H}\right]$-glucosamine was assessed. Data are presented as mean \pm SEM, $\mathrm{n}=4$ for each treatment. ${ }^{*}: \mathrm{p}<0.005$ compared with control values; **: $p<0.01$ compared with TGF- $\beta 1$-stimulated values.

Later stages of IPAH are dominated by vascular remodelling and characterised by enhanced proliferation and ECM synthesis of PASMC, with increased endothelial cell apoptosis [4, 5]. GAGs, major constituents of the lung ECM, have recently been shown to play a significant role in inflammatory and noninflammatory lung diseases, exhibiting spatiotemporally distinct effects on epithelial or mesenchymal cell types [8,9]. GAGs regulate hydration and water homeostasis, maintain cell and tissue structure and function, modulate inflammatory responses and influence tissue repair and remodelling [8, 13]. This led the current authors to hypothesise that differential

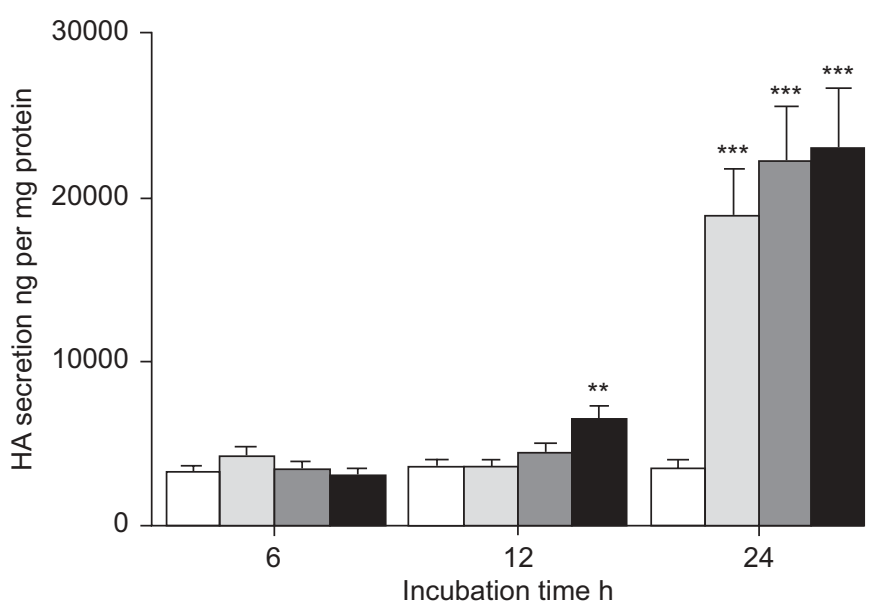

FIGURE 6. Effect of transforming growth factor (TGF)- $\beta 1$ on hyaluronic acid (HA) secretion by pulmonary arterial smooth muscle cells (PASMC). Subconfluent primary PASMC were incubated without TGF- $\beta 1(\square)$, or with $0.2 \mathrm{ng} \cdot \mathrm{mL}^{-1}(\square)$, $2 \mathrm{ng} \cdot \mathrm{mL}^{-1}$ (回) or $10 \mathrm{ng} \cdot \mathrm{mL}^{-1}$ ( $)$ for 6,12 or $24 \mathrm{~h}$. HA was measured in cell culture supernatants by ELISA. Data are presented as mean \pm SEM of four independent experiments. ${ }^{* *}: p<0.01 ;{ }^{* * *}: p<0.001$.

secretion of GAG by PASMC is associated with vascular remodelling in IPAH.

In the present study, IPAH lung tissues exhibited a significantly increased HA content, the major GAG produced by PASMC. While the relative amount of HA was significantly increased, the levels of the sulphated GAGs heparan, dermatan and chondroitin sulphate were decreased, indicating an increased ratio of nonsulphated to sulphated GAG. The increased HA content of IPAH lung tissues was associated with increased and decreased gene expression of Has1 and Hyal1, respectively. While no relationship was sought between the HA amount and the severity of IPAH (e.g. assessed by pulmonary arterial pressure or pulmonary vascular resistance), the current authors are confident that HA exerts a pathophysiological role, at least in the late and/or severe stages of IPAH that transplant patients exhibit.

Similar changes were observed in primary human PASMC cultured from the lungs of IPAH patients, which demonstrated a significant decrease in Hyal1 mRNA levels compared with PASMC obtained from transplant donor lungs. In addition, stimulation of PASMC with TGF- $\beta 1$, a growth factor involved in the pathogenesis of IPAH [3, 4], led to increased Has1 gene expression as early as $2 \mathrm{~h}$ after stimulation. Since increased HA staining was observed in actively remodelled pulmonary arteries, it is tempting to speculate that HA secretion by PASMC directly influences endothelial and smooth muscle cell proliferation and may control vasoreactive responses in IPAH.

This is substantiated by the fact that selective overexpression of Has2 in smooth muscle cells in transgenic mice resulted in significantly increased HA content in the tunica media, enhanced mechanical stiffness and strength and accelerated development of atherosclerosis [28]. Similar effects were reported for the HA receptor CD44, using CD44-null mice. CD44 expression promoted susceptibility to atherosclerosis, recruitment of macrophages and smooth muscle cell activation 


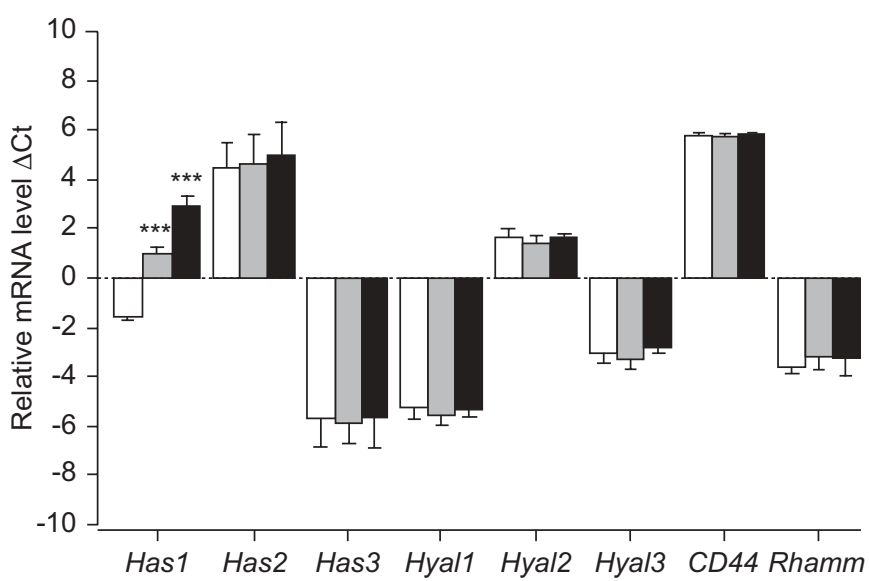

FIGURE 7. Induction of hyaluronan synthase (Has)1 gene expression in transforming growth factor (TGF)- $\beta 1$-stimulated pulmonary arterial smooth muscle cells (PASMC). mRNA was extracted from primary human PASMC $(n=3)$ without TGF- $\beta 1(\square)$ or from PASMC stimulated for $2 \mathrm{~h}(\square)$ or $6 \mathrm{~h}(\mathbf{\square})$ with $2 \mathrm{ng} \cdot \mathrm{mL}^{-1} \mathrm{TGF}-$ $\beta 1$. The relative expression levels of Has1-3, hyaluronoglucosaminidase (Hyal)1-3, CD44 and the receptor for hyaluronan-mediated motility (Rhamm) were determined by quantitative RT-PCR. Data are presented as mean \pm SEM relative expression level, as change in threshold cycle $(\Delta \mathrm{Ct})$ values. ${ }^{* * *}: \mathrm{p}<0.001$

and proliferation [27]. While no pulmonary vascular changes have been investigated in either previous study, it is highly likely that similar changes in HA and CD44 content in human pulmonary arteries, as reported in the present study, also affect vascular stiffness and strength, hence further contributing to the increased resistance observed in IPAH.

How are the biological effects of HA induced? First, it is known to bind 1000 times its own weight in water, hence contributing to tissue hydration and water homeostasis [12, 22, 23]. Secondly, increased HA synthesis and turnover represents an early response during lung inflammation in general and mesenchymal cell activation in particular $[8,12]$. HA regulates cell migration, differentiation and proliferation via interaction with specific cell-surface receptors (CD44 or RHAMM) [12, 22], but also via interaction with toll-like receptors 2 and 4 [14]. The interaction of HA with CD44 regulates leukocyte rolling and activation, as well as tumour metastasis. Furthermore, CD44dependent clearance of HA fragments is crucial in resolving lung inflammation in the bleomycin model of lung injury [26], demonstrating an essential role for CD44 in the resolution phase of inflammation.

It is of interest to note that the biological effects of HA vary depending on its average molecular mass [12, 23]. Under physiological conditions, HA is a polymer of high average molecular mass $(>1,000 \mathrm{kDa})$. In contrast, HA fragments of lower molecular mass accumulate following tissue injury, which are cleared via binding to the cell surface receptor CD44. HA with lower molecular mass (300-500 kDa) has been reported to prolong the survival of eosinophils in vitro [33]. HA fragments $(<200 \mathrm{kDa})$ induce the expression of cytokines, chemokines or inducible nitric oxide synthase by macrophages [34], affects ECM turnover in murine alveolar macrophages [34] and stimulates TGF- $\beta 1$ synthesis [33]. It has been shown that fragmented $\mathrm{HA}$ with an average molecular mass of
$250 \mathrm{kDa}$ induces the expression of inflammatory genes [35], while HA of higher molecular weight exhibited the opposite effect and suppressed chemokine expression [23]. Therefore, it would be of interest to elucidate in future studies whether HA expressed in the vascular system of control donor lung specimen is of different average molecular weight than in IPAH specimens. In this context, dysregulation of Has/Hyal expression and/or activity may lead to the generation of HA of different molecular masses, thereby exhibiting distinct biological effects, e.g. facilitating PASMC migration and proliferation, which potentially contribute to the pathogenesis of IPAH.

The aforementioned in vivo experiments were supported by the current observations in primary cultures of PASMC. It was found that TGF- $\beta 1$, but not BMP-2, significantly stimulated total GAG synthesis and HA secretion, an effect which coincided with an increased Has1 gene expression. The TGF$\beta 1$-dependent increase in GAG synthesis was mediated via the Smad and p38 MAPK pathways. The current results are in agreement with previous studies in human fibroblast-like synoviocytes, which have revealed that TGF- $\beta 1$ is a potent stimulus for Has1 expression. Furthermore, blocking p38 MAPK inhibited TGF- $\beta 1$-induced Has1 expression by $90 \%$ [36], which underlines the importance of the p38 signalling pathway for TGF- $\beta 1$-regulated expression of Has isoforms. Since TGF- $\beta 1$ is a potent stimulus for PASMC migration, Has1mediated HA synthesis may represent a necessary step for PASMC activation and migration. The aforementioned changes in Has/Hyal expression, along with the change in HA synthesis and content in IPAH, may also potentially result from the tissue hypoxia observed in IPAH. Notably, it has previously been reported that hypoxia potentiates GAG synthesis by primary lung fibroblasts induced by TGF- $\beta$ or PDGF-BB [16, 37], suggesting that hypoxia is a synergistic regulator of the increased GAG deposition observed in IPAH.

In conclusion, the results of the present study demonstrate an increased hyaluronic acid content in lungs from idiopathic pulmonary arterial hypertension patients, which was associated with increased hyaluronan synthase 1 and decreased hyaluronoglucosaminidase 1 gene expression. Synergistic regulation of glycosaminoglycan-metabolising enzymes in favour of accumulation may, thus, regulate pathological remodelling in idiopathic pulmonary arterial hypertension by favouring the activation state of pulmonary arterial smooth muscle cells.

\section{REFERENCES}

1 Gaine SP, Rubin LJ. Primary pulmonary hypertension. Lancet 1998; 352: 719-725.

2 Humbert M, Sitbon O, Simonneau G. Treatment of pulmonary arterial hypertension. N Engl J Med 2004; 351: 1425-1436.

3 Eickelberg O, Morty RE. Transforming growth factor- $\beta$ / bone morphogenic protein signaling in pulmonary arterial hypertension: remodeling revisited. Trends Cardiovasc Med 2007; 17: 263-269.

4 Humbert M, Morrell NW, Archer SL, et al. Cellular and molecular pathobiology of pulmonary arterial hypertension. J Am Coll Cardiol 2004; 43: Suppl. 12, 13S-24S. 
5 Olschewski H, Rose F, Grünig E, et al. Cellular pathophysiology and therapy of pulmonary hypertension. J Lab Clin Med 2001; 138: 367-377.

6 Hassoun PM. Deciphering the "matrix" in pulmonary vascular remodelling. Eur Respir J 2005; 25: 778-779.

7 Rabinovitch M. Pathobiology of pulmonary hypertension. Extracellular matrix. Clin Chest Med 2001; 22: 433-449.

8 Noble PW, Jiang D. Matrix regulation of lung injury, inflammation, and repair: the role of innate immunity. Proc Am Thorac Soc 2006; 3: 401-404.

9 Laurent GJ, Chambers RC, Hill MR, McAnulty RJ. Regulation of matrix turnover: fibroblasts, forces, factors and fibrosis. Biochem Soc Trans 2007; 35: 647-651.

10 McAnulty RJ, Laurent GJ. Collagen synthesis and degradation in vivo. Evidence for rapid rates of collagen turnover with extensive degradation of newly synthesized collagen in tissues of the adult rat. Coll Relat Res 1987; 7: 93-104.

11 Bosman FT, Stamenkovic I. Functional structure and composition of the extracellular matrix. J Pathol 2003; 200: 423-428.

12 Jiang D, Liang J, Noble PW. Hyaluronan in tissue injury and repair. Annu Rev Cell Dev Biol 2007; 23: 435-461.

13 Souza-Fernandes AB, Pelosi P, Rocco PR. Bench-to-bedside review: the role of glycosaminoglycans in respiratory disease. Crit Care 2006; 10: 237.

14 Jiang D, Liang J, Fan J, et al. Regulation of lung injury and repair by Toll-like receptors and hyaluronan. Nat Med 2005; 11: 1173-1179.

15 Papakonstantinou E, Roth M, Kokkas B, Papadopoulos C, Karakiulakis G. Losartan inhibits the angiotensin IIinduced modifications on fibrinolysis and matrix deposition by primary human vascular smooth muscle cells. J Cardiovasc Pharmacol 2001; 38: 715-728.

16 Papakonstantinou E, Karakiulakis G, Tamm M, Perruchoud AP, Roth M. Hypoxia modifies the effect of PDGF on glycosaminoglycan synthesis by primary human lung cells. Am J Physiol Lung Cell Mol Physiol 2000; 279: L825-L834.

17 Hance AJ, Crystal RG. The connective tissue of lung. Am Rev Respir Dis 1975; 112: 657-711.

18 Itano N, Sawai T, Yoshida M, et al. Three isoforms of mammalian hyaluronan synthases have distinct enzymatic properties. J Biol Chem 1999; 274: 25085-25092.

19 Csóka AB, Frost GI, Wong T, Stern R. Purification and microsequencing of hyaluronidase isozymes from human urine. FEBS Lett 1997; 417: 307-310.

20 Papakonstantinou E, Roth M, Block LH, Mirtsou-Fidani V, Argiriadis P, Karakiulakis G. The differential distribution of hyaluronic acid in the layers of human atheromatic aortas is associated with vascular smooth muscle cell proliferation and migration. Atherosclerosis 1998; 138: 79-89.

21 Lee JY, Spicer AP. Hyaluronan: a multifunctional, megaDalton, stealth molecule. Curr Opin Cell Biol 2000; 12: $581-586$.
22 Toole BP. Hyaluronan: from extracellular glue to pericellular cue. Nat Rev Cancer 2004; 4: 528-539.

23 Turino GM, Cantor JO. Hyaluronan in respiratory injury and repair. Am J Respir Crit Care Med 2003; 167: 1169-1175.

24 Turley EA, Noble PW, Bourguignon LY. Signaling properties of hyaluronan receptors. J Biol Chem 2002; 277: 45894592.

25 Day AJ, Prestwich GD. Hyaluronan-binding proteins: tying up the giant. J Biol Chem 2002; 277: 4585-4588.

26 Teder P, Vandivier RW, Jiang D, et al. Resolution of lung inflammation by CD44. Science 2002; 296: 155-158.

27 Cuff CA, Kothapalli D, Azonobi I, et al. The adhesion receptor CD44 promotes atherosclerosis by mediating inflammatory cell recruitment and vascular cell activation. J Clin Invest 2001; 108: 1031-1040.

28 Chai S, Chai Q, Danielsen CC, et al. Overexpression of hyaluronan in the tunica media promotes the development of atherosclerosis. Circ Res 2005; 96: 583-591.

29 Gouëffic Y, Guilluy C, Guérin P, Patra P, Pacaud P, Loirand G. Hyaluronan induces vascular smooth muscle cell migration through RHAMM-mediated PI3K-dependent Rac activation. Cardiovasc Res 2006; 72: 339-348.

30 Zakrzewicz A, Hecker M, Marsh LM, et al. Receptor for activated C-kinase 1, a novel interaction partner of type II bone morphogenetic protein receptor, regulates smooth muscle cell proliferation in pulmonary arterial hypertension. Circulation 2007; 115: 2957-2968.

31 Bitter T, Muir HM. A modified uronic acid carbazole reaction. Anal Biochem 1962; 4: 330-334.

32 Papakonstantinou E, Karakiulakis G, Roth M, Block LH. Platelet-derived growth factor stimulates the secretion of hyaluronic acid by proliferating human vascular smooth muscle cells. Proc Natl Acad Sci USA 1995; 92: 9881-9885.

33 Ohkawara Y, Tamura G, Iwasaki T, Tanaka A, Kikuchi T, Shirato K. Activation and transforming growth factor- $\beta$ production in eosinophils by hyaluronan. Am J Respir Cell Mol Biol 2000; 23: 444-451.

34 McKee CM, Penno MB, Cowman M, et al. Hyaluronan (HA) fragments induce chemokine gene expression in alveolar macrophages. The role of HA size and CD44. J Clin Invest 1996; 98: 2403-2413.

35 Tammi MI, Day AJ, Turley EA. Hyaluronan and homeostasis: a balancing act. J Biol Chem 2002; 277: 4581-4584.

36 Stuhlmeier KM, Pollaschek C. Differential effect of transforming growth factor- $\beta$ (TGF- $\beta$ ) on the genes encoding hyaluronan synthases and utilization of the p38 MAPK pathway in TGF- $\beta$-induced hyaluronan synthase 1 activation. J Biol Chem 2004; 279: 8753-8760.

37 Papakonstantinou E, Roth M, Tamm M, Eickelberg O, Perruchoud AP, Karakiulakis G. Hypoxia differentially enhances the effects of transforming growth factor-beta isoforms on the synthesis and secretion of glycosaminoglycans by human lung fibroblasts. J Pharmacol Exp Ther 2002; 301: 830-837. 